\title{
A possible role of low regulatory $T$ cells in anti-acetylcholine receptor antibody positive myasthenia gravis after bone marrow transplantation
}

Masahiko Fukatsu', Takenobu Murakami ${ }^{1 *}$, Hiroshi Ohkawara², Shunichi Saito ${ }^{3}, K^{2}$ azuhiko Ikeda ${ }^{2,3}$, Suguru Kadowaki ${ }^{1}$, Itaru Sasaki ${ }^{1}$, Mari Segawa' ${ }^{1}$, Tomoko Soeda' , Akihiko Hoshi ${ }^{1}$, Hiroshi Takahashi², Akiko Shichishima-Nakamura², Kazuei Ogawa², Yoshihiro Sugiura' ${ }^{2}$ Hitoshi Ohto ${ }^{3}$, Yasuchika Takeishi', Takayuki Ikezoe ${ }^{2}$ and Yoshikazu Ugawa ${ }^{1,5}$

\begin{abstract}
Background: Chronic graft-versus-host disease (GVHD) appears several months following allogenic hematopoietic stem cell transplantation (HSCT) and is clinically analogous to autoimmune disorder. Polymyositis is a common neuromuscular disorder in chronic GVHD, but myasthenia gravis (MG) is extremely rare. Hence, its pathophysiology and treatment have not been elucidated.

Case presentation: A 63-year-old man with a history of chronic GVHD presented with ptosis, dropped head, and dyspnea on exertion, which had worsened over the previous several months. He showed progressive decrement of compound muscle action potential in the deltoid muscle evoked by $3-\mathrm{Hz}$ repetitive nerve stimulation, a positive edrophonium test, and elevated levels of serum anti-acetylcholine receptor antibodies, which suggested a diagnosis of generalized MG. No thymoma was found. Flow cytometric analysis revealed a remarkable depletion of peripheral Tregs (CD4 ${ }^{+} \mathrm{CD} 25^{\text {high }} \mathrm{FOXP3}^{+}$cells, $0.24 \%$ of the total lymphocytes). Administration of prednisolone and tacrolimus was insufficient to alleviate his symptoms; however, the use of rituximab successfully improved his condition.

Conclusions: Myasthenic symptoms appeared in the process of tapering prednisolone for the treatment of chronic GVHD, supporting the diagnosis of MG associated with chronic GVHD. The present case proposes a possibility that reduction of Tregs might contribute to the pathogenesis of MG underlying chronic GVHD. Immunotherapy with rituximab is beneficial for treatment of refractory MG and GVHD.
\end{abstract}

Keywords: Myasthenia gravis, Hematopoietic cell transplantation, Graft-versus-host disease, Regulatory T cells, Rituximab, Anti-acetylcholine receptor antibody

\section{Background}

Myasthenia gravis (MG) is a neuromuscular disorder characterized by muscle weakness and pathological fatigability of skeletal muscles. The pathophysiology of MG is defined as the production of autoantibodies blocking acetylcholine receptors at the neuromuscular junction [1]. Chronic graft-versus-host disease (GVHD) is mediated by the

\footnotetext{
* Correspondence: takebou@fmu.ac.jp

'Department of Neurology, Fukushima Medical University, 1 Hikariga-oka,

Fukushima, Fukushima 960-1295, Japan

Full list of author information is available at the end of the article
}

reactivation of donor $\mathrm{T}$ cells against recipient tissues and appears several months after allogenic hematopoietic stem cell transplantation (HSCT) in most cases [2]. The major organs involved in GVHD include the skin, gastrointestinal tract, and liver, whereas chronic GVHD features a wide variety of autoimmune disorders, including Sjögren syndrome, scleroderma, bronchiolitis obliterans, and immune cytopenias [3]. Chronic GVHD also affects neuromuscular system. In fact, polymyositis is a common neuromuscular disease present in chronic GVHD; however, MG is extremely rare. Although the 2015 
National Institutes of Health Consensus Conference categorized MG under "other features or unclassified entities" of the signs and symptoms for diagnosis and staging of chronic GVHD, there have been a limited number of MG cases following allogeneic HSCT [4], and its pathophysiology and treatment approach have not yet been well established.

We present a case of chronic GVHD developing generalized MG that was successfully treated with advanced immunotherapy. The current case revealed a marked reduction of regulatory $\mathrm{T}$ cells (Tregs), suggesting the possible pathogenesis of MG in patients with chronic GVHD.

\section{Case presentation}

A 63-year-old man without familial history of MG was diagnosed with secondary acute myeloid leukemia that originated from myelodysplastic/myeloproliferative neoplasms, unclassifiable 2 years prior to the current presentation. He was then treated with intensive chemotherapy, and underwent allogeneic HSCT from a human leukocyte antigen (HLA)-matched unrelated donor in the following year. Prophylaxis against GVHD consisted of tacrolimus and short-term methotrexate. He achieved remission of acute GVHD, and tacrolimus was discontinued on day 86 . He then developed mild chronic GVHD of the skin and liver at 7 and 12 months after the transplantation, respectively. Fourteen months after the transplantation, he was admitted to our hospital due to progressive bilateral pleural effusion, which was attributed to pleuritis related to chronic GVHD, and was successfully treated with intravenous methylprednisolone pulse therapy (mPSL) $(1 \mathrm{~g}$ during the course of 3 days) followed by oral prednisolone $(1 \mathrm{mg} / \mathrm{kg} /$ day). During the process of tapering oral prednisolone to $7.5 \mathrm{mg} /$ day (20 months after the transplantation), the patient began to complain of bilateral ptosis, dropped head, and dyspnea on exertion, which continued to worsen, and he was admitted to our hospital.

On examination, his general condition was normal, except for the presence of sinus tachycardia (106/min). $\mathrm{He}$ had a moon face appearance as well as increased pigmentation and sclerotic changes on the skin. He was alert and had normal cognitive function. The patient had ptosis, dropped head, and mild bilateral weakness involving the craniocervical muscles and deltoid muscles (grade 4 as measured by the Manual Muscle Strength Testing) with fatigability. However, no bulbar symptoms were noted.

Blood sample tests showed an elevated anti-acetylcholine receptor (AChR) antibody $(14.0 \mathrm{nmol} / \mathrm{L})$, but negative anti-muscle specific kinase (anti-MuSK) antibody. His HLA genotype consisted of $\mathrm{A}^{*} 24: 02-\mathrm{B}^{*} 52: 01-\mathrm{C}^{*} 12: 02$ DRB1*12:01 and A*24:02-B*52:01-C*12:02-DRB1*15:02. Although the arterial blood carbon dioxide concentration was within the normal range, a pulmonary function test revealed a substantial reduction of vital capacity (VC) at $1.69 \mathrm{~L}$ (45.4\% predicted). Polymerase chain reaction analysis of short tandem repeat sequences for peripheral blood showed $100 \%$ donor chimerism. Chest computed tomography suggested mild emphysematous changes in the lung field, but thymoma was not found. Intravenous injection of edrophonium remarkably improved the patient's ptosis and dropped head. An electrophysiological study showed $20.0 \%$ area decrement of compound muscle action potentials (CMAP) from the right deltoid muscle by $3-\mathrm{Hz}$ repetitive axillary nerve stimulation. These findings confirmed a diagnosis of generalized MG with Myasthenia Gravis Foundation of America clinical classification IIb, quantitative MG score 14 out of 36 , and MG-ADL score 8 out of 24 .

Flow cytometric analyses were performed by using the patient's peripheral blood because depletion of Tregs after HSCT has been reported to be valuable in predicting chronic GVHD severity [5-7]. The Treg population in the peripheral blood, defined as $\mathrm{CD} 4^{+} \mathrm{CD} 25^{\text {high }} \mathrm{FOXP}^{+}$cells, was $0.24 \%$ of the total lymphocytes (Fig. 1). This proportion was lower than that of our post-HSCT patients (mean \pm SD $0.51 \pm 0.15 \%$ ) and of healthy subjects $(0.94 \pm 0.19 \%)[5]$.

Considering progression to myasthenic crisis, intravenous immunoglobulin was initially administered $(0.4 \mathrm{~g} / \mathrm{kg}$ for 5 days) and the patient showed mild responses for his ptosis and dropped head, but his fatigability and dyspnea on exertion remained unchanged. Subsequent mPSL pulse treatment ( $1 \mathrm{~g}$ for 2 days) exacerbated MG symptoms. We started pyridostigmine $180 \mathrm{mg} /$ day with tacrolimus $3 \mathrm{mg} /$ day, and consequently, his fatigability gradually improved and VC increased to $2.35 \mathrm{~L}(63.1 \%$ predicted) on the 28th hospital day. Follow-up electrophysiological study showed disappearance of significant CMAP decrement (4.5\% area decrease). However, these improvements were insufficient for his daily activity. Follow-up anti-AChR antibody was still elevated to $18.0 \mathrm{nmol} / \mathrm{L}$ on the $22 \mathrm{nd}$ hospital day. The patient was treated with an increased oral prednisolone dose of $50 \mathrm{mg} /$ day and intravenous mPSL pulse (1 $\mathrm{g}$ for 3 days), and anti-AChR antibody was decreased to $9.7 \mathrm{nmol} / \mathrm{L}$ on the 55th hospital day. Finally, he was administered four courses of weekly rituximab $375 \mathrm{mg} / \mathrm{m}^{2}$, and his fatigability and weakness continued to improve steadily without pyridostigmine. He was discharged on the 92nd hospital day, receiving tacrolimus $3 \mathrm{mg} /$ day and prednisolone $20 \mathrm{mg} /$ day (Fig. 2). Five months after discharge, minimal manifestations remained, with a VC of $2.95 \mathrm{~L}$ (79.2\% predicted), and he continued to take oral prednisolone at a dose of $10 \mathrm{mg} /$ day and tacrolimus at $3 \mathrm{mg} /$ day. Titers of anti-AChR antibody were steadily reduced (4.6, 3.7, and $3.2 \mathrm{nmol} / \mathrm{L}$ on 3,6 , and 9 months after discharge). 

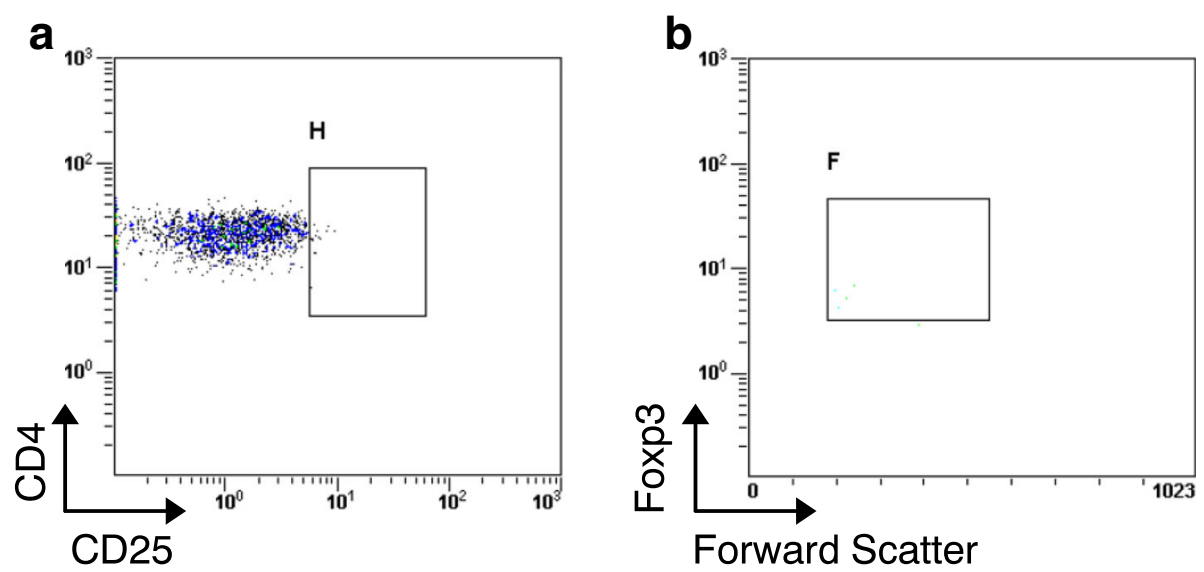

Fig. 1 Decreased $C D 4^{+} C D 25^{\text {high }} \mathrm{FOXP}^{+}$cells (Tregs) in peripheral blood mononuclear cells from the patient. a Reduced proportion of $\mathrm{CD} 25^{\text {high }}$ cells in gated $\mathrm{CD} 4^{+}$fraction in peripheral blood mononuclear cells (gate H). b Most CD4 ${ }^{+} \mathrm{CD} 25^{\text {high }}$ cells in gate $\mathrm{H}(>90 \%$ ) were positive for Foxp3 (gate F)

\section{Discussion and conclusions}

MG is a very rare complication following HSCT, with an occurrence of less than $1 \%$. Myasthenic symptoms typically develop between 22 and 60 months after transplantation [8] and most reported cases are associated with the existence of other symptoms of chronic GVHD, as MG is rarely the sole manifestation [9]. Myasthenic symptoms appear after the discontinuation or tapering of immunosuppressive agents [10], as in the present case. Patients with aplastic anemia as a background would have an increased risk of developing MG after transplantation [11]. Patients with specific HLAs (HLA Cw1, Cw7 or DR2) and a family history of MG are also at an increased risk of developing MG after HSCT $[12,13]$. However, none of these risk factors was identified in the present case.

Most patients with MG associated with chronic GVHD test positive for anti-AChR antibodies. Approximately $20 \%$ of patients with chronic GVHD show positive anti-AChR antibody without myasthenic symptoms, indicating the existence of higher rates of subclinical MG [14]. In the present case, an elevated titer of antiAChR antibody supported the diagnosis of MG, and its titer decreased in parallel with the improvement of myasthenic symptoms after immunotherapies. A few reported patients with MG after transplantation revealed

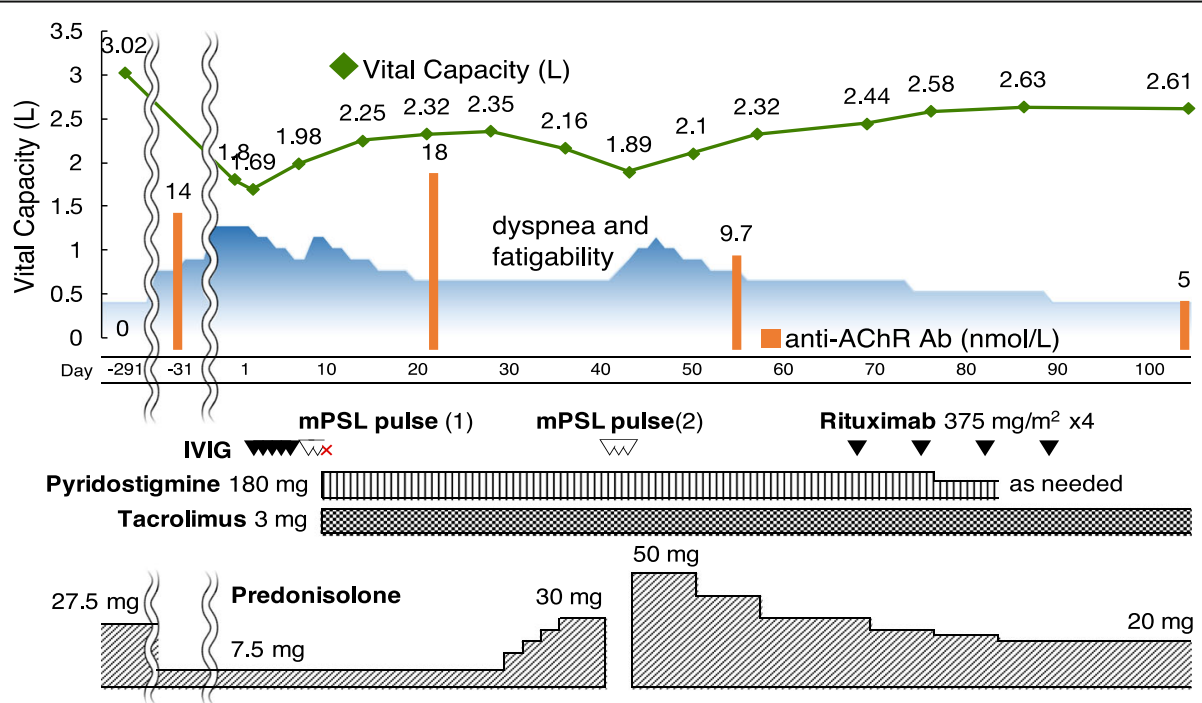

Fig. 2 Clinical courses of the present case. VC (in L) and anti-AChR antibody titer (in nmol/L) are shown in a line chart and a bar graph, respectively. Intravenous immunoglobulin was initially administered $(0.4 \mathrm{~g} / \mathrm{kg}$ for 5 days) with only moderate response. Two courses of mPSL pulse treatment ( $1 \mathrm{~g}$ for 2 to 3 days) rather exacerbated MG symptoms. Meanwhile, he was started on pyridostigmine $180 \mathrm{mg} /$ day and tacrolimus $3 \mathrm{mg} /$ day. Finally, he was administered four courses of weekly rituximab $375 \mathrm{mg} / \mathrm{m}^{2}$, and his fatigability and weakness continued to improve steadily without pyridostigmine 
other antibodies toward non-AChR components of the postsynaptic muscle endplate, e.g. anti-MuSK and anti-striated muscle antibodies [15, 16]. These findings suggest that pathogenic autoantibodies toward the neuromuscular junctions may be produced when discontinuing or tapering immunosuppressive treatments after transplantation.

A unique point in the present case was lower population of Tregs in the peripheral blood. Tregs are a subset of $\mathrm{T}$ lymphocytes that modulate the immune system and maintain tolerance to self-antigens $[17,18]$. The frequency of Tregs in the peripheral blood has been reported to negatively correlate with GVHD severity [6]. Absence of Tregs coupled with donor-derived $\mathrm{T}$ cells leads to development of GVHD [19]. The number of Tregs in the peripheral blood decreases in untreated MG and is normalized by immunotherapy [20]. A functional impairment of thymic Tregs has been reported in the thymus of patients with MG and may play a role in triggering the autoimmune process [21]. Recent studies have reported Treg dysfunction as well as its downstream signal transducer and activator of transcription pathway is associated with immunopathology of MG, and a Treg-based immunotherapeutic approach has been suggested for experimental models of MG [22-24]. We suspect that suppression of Tregs in the present case may have partly contributed to the pathogenesis of MG as a manifestation of chronic GVHD.

Recently, several reports have shown that rituximab, a monoclonal antibody against $B$ cell surface antigen CD20, could be an effective treatment for patients with refractory MG $[25,26]$. Rituximab therapy also reduces the incidence of GVHD following allogeneic HSCT and exhibits a beneficial effect on steroid-refractory GVHD [27]. Although rituximab itself directly interacts with B cells, B cell depletion subsequently leads to expansion of Tregs and suppression of autoreactive $\mathrm{T}$ cells [28]. Additionally, treatment with rituximab was shown to be successful in two cases of MG associated with chronic GVHD [27, 29]. This evidence supports the utility of rituximab for refractory GVHD and MG against conventional immunotherapies in the present case.

In conclusion, we reported a rare case of chronic GVHD developing systemic MG after allogenic HSCT. Appearance of myasthenic symptoms during the process of tapering prednisolone for the treatment of chronic GVHD is a key feature of MG associated with chronic GVHD. We hypothesize that the reduced number of Tregs might play a possible role in the pathogenesis of MG and chronic GVHD. Immunotherapy with rituximab led to improvements of the patient's myasthenic symptoms, supporting the utility of rituximab for refractory MG and GVHD.

\section{Abbreviations}

AChR: Anti-acetylcholine receptor; anti-MuSK: Anti-muscle specific kinase: CMAP: Compound muscle action potentials; GVHD: Graft-versus-host disease; HLA: Human leukocyte antigen; HSCT: Hematopoietic stem cell transplantation; MG: Myasthenia gravis; mPSL: Methylprednisolone; Tregs: Regulatory T cells; VC: Vital capacity

\section{Acknowledgments}

Dr. Fukatsu received Young Investigator Award in the 112th Annual Meeting of the Japanese Society of Internal Medicine (2015 Kyoto). The authors wish to thank the Elsevier Language Editing for scientific English editing.

\section{Funding}

Dr. Murakami has received research funding from the Research Project Grant-in-aid for Scientific Research from the Ministry of Education, Culture, Sports, Science and Technology No. 15H01563, 16 K09724, the SENSHIN Medical Research Foundation, and the Mitsubishi Tanabe Pharma Corporation. Dr. Hoshi was supported by grants from the Research Project Grant-in-aid for Scientific Research from the Ministry of Education, Culture, Sports, Science and Technology No. 26461314. Dr. Ugawa was supported by grants from the Research Project Grant-in-aid for Scientific Research from the Ministry of Education, Culture, Sports, Science and Technology No. 22390181, 25,293,206, 15H05881, the Research Committee on Degenerative Ataxia from the Ministry of Health and Welfare of Japan, the Uehara Memorial Foundation, and the Novartis Foundation (Japan) for the Promotion of Science.

\section{Availability of data and materials}

Not applicable.

\section{Authors' contributions}

$M F, T M, H O$ : research project conception, organization, execution and writing of the first draft. SS, KI, SK, IS, MS, TS, AH, HT, ASN, KO, YS, HO, and YT: research execution, manuscript review and critique. TI and YU: research project organization and execution, manuscript review and critique. All authors read and approved the final manuscript.

\section{Competing interests}

The authors declare that they have no competing interests.

\section{Consent for publication}

Written informed consent was obtained from the wife of the patient for publication of this case report and any accompanying images. A copy of the written consent is available for review by the editor of this journal.

Ethics approval and consent to participate

Not applicable.

\section{Publisher's Note}

Springer Nature remains neutral with regard to jurisdictional claims in published maps and institutional affiliations.

\section{Author details}

1Department of Neurology, Fukushima Medical University, 1 Hikariga-oka, Fukushima, Fukushima 960-1295, Japan. ²Department of Hematology, Fukushima Medical University, Fukushima, Japan. ${ }^{3}$ Department of Blood Transfusion and Transplantation Immunology, Fukushima Medical University, Fukushima, Japan. ${ }^{4}$ Department of Cardiovascular Medicine, Fukushima Medical University, Fukushima, Japan. ${ }^{5}$ Fukushima Global Medical Science Center, Advanced Clinical Research Center, Fukushima Medical University, Fukushima, Japan.

Received: 9 February 2017 Accepted: 9 May 2017

Published online: 15 May 2017

\section{References}

1. Gilhus NE, Verschuuren JJ. Myasthenia gravis: subgroup classification and therapeutic strategies. Lancet Neurol. 2015;14(10):1023-36.

2. Jamil MO, Mineishi S. State-of-the-art acute and chronic GVHD treatment. Int J Hematol. 2015;101(5):452-66. 
3. Vigorito AC, Campregher PV, Storer BE, Carpenter PA, Moravec CK, Kiem HP, Fero ML, Warren EH, Lee SJ, Appelbaum FR, et al. Evaluation of $\mathrm{NIH}$ consensus criteria for classification of late acute and chronic GVHD. Blood. 2009;114(3):702-8

4. Jagasia MH, Greinix HT, Arora M, Williams KM, Wolff D, Cowen EW, Palmer J, Weisdorf D, Treister NS, Cheng GS, et al. National Institutes of Health consensus development project on criteria for clinical trials in chronic graftversus-host disease: I. The 2014 diagnosis and staging working group report. Biol Blood Marrow Transplant. 2015;21(3):389-401. e381

5. Ngoma AM, Ikeda K, Hashimoto Y, Mochizuki K, Takahashi H, Sano H, Matsumoto H, Noji H, Saito S, Kikuta A, et al. Impaired regulatory T cell reconstitution in patients with acute graft-versus-host disease and cytomegalovirus infection after allogeneic bone marrow transplantation. Int J Hematol. 2012;95(1):86-94.

6. Li Q, Zhai Z, Xu X, Shen Y, Zhang A, Sun Z, Liu H, Geng L, Wang Y. Decrease of CD4(+)CD25(+) regulatory $T$ cells and TGF-beta at early immune reconstitution is associated to the onset and severity of graft-versus-host disease following allogeneic haematogenesis stem cell transplantation. Leuk Res. 2010;34(9):1158-68.

7. Takahashi H, Ikeda K, Ogawa K, Saito S, Ngoma AM, Mashimo Y, Ueda K, Furukawa M, Shichishima-Nakamura A, Ohkawara H, et al. CD4+ T cells in aged or thymectomized recipients of allogeneic stem cell transplantations. Biol Res. 2015;48:41.

8. Grauer O, Wolff D, Bertz H, Greinix H, Kuhl JS, Lawitschka A, Lee SJ, Pavletic SZ, Holler E, Kleiter I. Neurological manifestations of chronic graft-versushost disease after allogeneic haematopoietic stem cell transplantation: report from the consensus conference on clinical practice in chronic graftversus-host disease. Brain. 2010;133(10):2852-65.

9. Baron F, Sadzot B, Wang F, Beguin Y. Myasthenia gravis without chronic GVHD after allogeneic bone marrow transplantation. Bone Marrow Transplant. 1998;22(2):197-200.

10. Bolger GB, Sullivan KM, Spence AM, Appelbaum FR, Johnston R, Sanders JE, Deeg HJ, Witherspoon RP, Doney KC, Nims J, et al. Myasthenia gravis after allogeneic bone marrow transplantation: relationship to chronic graftversus-host disease. Neurology. 1986;36(8):1087-91.

11. Nelson KR, McQuillen MP. Neurologic complications of graft-versus-host disease. Neurol Clin. 1988;6(2):389-403.

12. Dowell JE, Moots PL, Stein RS. Myasthenia gravis after allogeneic bone marrow transplantation for lymphoblastic lymphoma. Bone Marrow Transplant. 1999;24(12):1359-61.

13. Mackey JR, Desai S, Larratt L, Cwik V, Nabholtz JM. Myasthenia gravis in association with allogeneic bone marrow transplantation: clinical observations, therapeutic implications and review of literature. Bone Marrow Transplant. 1997;19(9):939-42.

14. Smith Cl, Norberg R, Moller G, Lonnqvist B, Hammarstrom L. Autoantibody formation after bone marrow transplantation. Comparison between acetylcholine receptor antibodies and other autoantibodies and analysis of HLA and gm markers. Eur Neurol. 1989;29(3):128-34.

15. Hon C, Mak W, Kwok AK, Au WY. Immunological and electrophysiological investigations of severe ptosis after bone marrow transplantation. Bone Marrow Transplant. 2004;34(5):455-8.

16. Atassi N, Amato AA. Muscle-specific kinase (MuSK) antibody-associated myasthenia gravis after bone marrow transplantation. Muscle Nerve. 2008; 38(2):1074-5.

17. Vignali DA, Collison LW, Workman CJ. How regulatory T cells work. Nat Rev Immunol. 2008;8(7):523-32.

18. Wing K, Sakaguchi S. Regulatory T cells exert checks and balances on self tolerance and autoimmunity. Nat Immunol. 2010;11(1):7-13.

19. Chen X, Vodanovic-Jankovic S, Johnson B, Keller M, Komorowski R, Drobyski WR. Absence of regulatory T-cell control of $\mathrm{TH} 1$ and $\mathrm{TH} 17$ cells is responsible for the autoimmune-mediated pathology in chronic graftversus-host disease. Blood. 2007;110(10):3804-13

20. Fattorossi A, Battaglia A, Buzzonetti A, Ciaraffa F, Scambia G, Evoli A. Circulating and thymic CD4 CD25 T regulatory cells in myasthenia gravis: effect of immunosuppressive treatment. Immunology. 2005;116(1):134-41.

21. Balandina A, Lecart S, Dartevelle P, Saoudi A, Berrih-Aknin S. Functional defect of regulatory CD4(+)CD25+ T cells in the thymus of patients with autoimmune myasthenia gravis. Blood. 2005;105(2):735-41.

22. Souroujon MC, Aricha R, Feferman T, Mizrachi K, Reuveni D, Fuchs S. Regulatory $T$ cell-based immunotherapies in experimental autoimmune myasthenia gravis. Ann N Y Acad Sci. 2012;1274:120-6.
23. Thiruppathi M, Rowin J, Li Jiang Q, Sheng JR, Prabhakar BS, Meriggioli MN Functional defect in regulatory T cells in myasthenia gravis. Ann N Y Acad Sci. 2012;1274:68-76.

24. Alahgholi-Hajibehzad M, Oflazer P, Aysal F, Durmus H, Gulsen-Parman Y, Marx A, Deymeer F, Saruhan-Direskeneli G. Regulatory function of CD4 + CD25++ T cells in patients with myasthenia gravis is associated with phenotypic changes and STAT5 signaling: 1,25-Dihydroxyvitamin D3 modulates the suppressor activity. J Neuroimmunol. 2015;281:51-60.

25. Anderson D, Phan C, Johnston WS, Siddiqi ZA. Rituximab in refractory myasthenia gravis: a prospective, open-label study with long-term followup. Ann Clin Transl Neurol. 2016:3(7):552-5.

26. Ruzhansky KM, Brannagan TH 3rd. Neuromuscular complications of hematopoietic stem cell transplantation. Muscle Nerve. 2015;52(4):480-7.

27. Zaja F, Bacigalupo A, Patriarca F, Stanzani M, Van Lint MT, Fili C, Scime R, Milone G, Falda M, Vener C, et al. Treatment of refractory chronic GVHD with rituximab: a GITMO study. Bone Marrow Transplant. 2007;40(3):273-7.

28. Lund FE, Randall TD. Effector and regulatory B cells: modulators of CD4+ T cell immunity. Nat Rev Immunol. 2010;10(4):236-47.

29. Unal S, Sag E, Kuskonmaz B, Kesici S, Bayrakci B, Ayvaz DC, Tezcan I, Yalnizoglu D, Uckan D. Successful treatment of severe myasthenia gravis developed after allogeneic hematopoietic stem cell transplantation with plasma exchange and rituximab. Pediatr Blood Cancer. 2014;61(5):928-30.

\section{Submit your next manuscript to BioMed Central and we will help you at every step:}

- We accept pre-submission inquiries

- Our selector tool helps you to find the most relevant journal

- We provide round the clock customer support

- Convenient online submission

- Thorough peer review

- Inclusion in PubMed and all major indexing services

- Maximum visibility for your research

Submit your manuscript at www.biomedcentral.com/submit
Biomed Central 